\title{
Ocular defects in children with cerebral palsy
}

\author{
P D BLACK
}

\section{Summary and conclusions}

Children with cerebral palsy have a high incidence of ocular abnormalities. All such children should be examined by an ophthalmologist soon after cerebral palsy is diagnosed.

\section{Introduction}

The association of certain eye defects with cerebral palsy has been known since Little's early papers on the disease in 1834 . $^{1}$ Both squint and refractive errors are usually common in these children, ${ }^{23}$ and they should be screened for these defects as early as possible. In practice the detailed examination and treatment given to a neurologically normal child is often denied to children with cerebral palsy. This study concerns the ophthalmological findings in the children attending a Spastic Society school.

\section{Patients and methods}

All 117 children at the school had cerebral palsy, the type of which was not material, and all were educationally severely subnormal (IQ in the range 30-50). Their ages ranged from 6 to 16 years; 52 were girls and 65 boys.

The children were examined in familiar surroundings, with their nurse and, if necessary, their teacher present. The gross ocular motility, visual acuity, visual field, pupillary reactions, ability to match colours, refraction, and the media and fundi were examined.

Ocular movements were examined for saccades, pursuit, and dollseye movements where necessary. Squint was assessed by cover test for

Department of Ophthalmology, RAF Hospital Ely, Ely, Cambridge CB6 1DN

P D BLACK, MB, FRCs, consultant ophthalmic surgeon and honorary consultant ophthalmic surgeon, Addenbrooke's Hospital, Cambridge near and distance. The visual acuity was measured by the Sheridan Gardner test, with single optotypes, and where this was not possible (in about $20 \%$ of cases) with the Catford drum. The visual field was examined using the Juler Projection Scotometer. Colour sense was examined by asking the child to match a piece of coloured felt shown to him with one of nine colours. The refraction was performed some 40 minutes after the instillation of $1 \%$ cyclopentolate drops into the eyes, and the fundi were then examined with the indirect ophthalmoscope. An increased incidence of side effects of cyclopentolate in cerebral palsied children has been noted, ${ }^{4}$ but none was seen in this series.

Table I shows the incidence of visual defects found in the various types of cerebral palsy. Abnormalities often co-existed, in particular squint and refractive errors.

Table II shows the percentage of each group with no abnormality, refractive error, squint, nystagmus, and field defect.

\section{Discussion}

Only $20.5 \%$ of these children had normal eyes by a basic ophthalmological examination. Refractive errors accounted for many of these abnormalities. Fantl and Perlstein ${ }^{3}$ found that $40 \%$ of their children had refractive errors greater than \pm 2 dioptres. My study shows an incidence of nearly half. This figure is greater mainly because the limits in this series were +2 dioptres to -1 dioptre, but the incidence of the abnormalities is also known to increase with the severity of the cerebral palsy. ${ }^{5}$ Twenty-seven pairs of spectacles were prescribed-in addition to 14 children already wearing glasses.

Squints were found in just over half the children-a similar figure to Douglas, ${ }^{5}$ who examined a regional population of cerebral palsied children. The incidence is only $2-3 \%$ in the general population, so this is a very high figure. Sixteen out of 59 squints were clearly paralytic; most were sixth-nerve palsies, but there were three third-nerve palsies and one child with a fourth-nerve palsy. In many cases of paralytic squints concomitance develops with the passage of time; so that in any series with a high proportion of young patients the incidence of obvious paralytic squints will be higher than in a comparable series of older patients. 
Of more importance, 16 children had an amblyopic eye with a vision of $6 / 36$ or less, associated with squint or anisometropia (unequal refractive error), that had not had the benefit of any treatment. Such abnormalities are easily overlooked in children with other more gross conditions, but the identification of ocular abnormalities likely to lead to amblyopia at an early age is important so that treatment can be started. The chance of obtaining binocular vision in such children is an ideal rather than a practicality, but every effort should still be made to obtain good vision in two eyes rather than one, since the nature of the child's underlying disability will render it accident prone.

Nystagmus was present in 19 children (16\%)-rather higher than in other series. It was present in half the children with ataxic cerebral palsy. Seven patients had ocular nystagmus compared with other series. Douglas, ${ }^{5}$ however, had an overall incidence of $59^{\circ}$ abnormality in all grades of severity of cerebral palsy and Schacat $68^{\circ}$ in children with moderate physical handicap and an IQ of greater than 70. The education of children with cerebral palsy relies heavily on visual stimulation, and identification of visual defects at an early stage is important for three reasons. Firstly, the most common defects are amenable to treatment. Secondly, identification of defects, particularly those of acuity and field, may have a bearing on the child's assessment and education. Thirdly, ocular abnormalities may shed some light on the precise diagnosis. In this series a high proportion of the children had never been examined by an ophthalmologist. All children with cerebral palsy should have such an examination soon after cerebral palsy is first diagnosed.

TABLE I-Incidence of visual defects in types of cerebral palsy in 117 patients

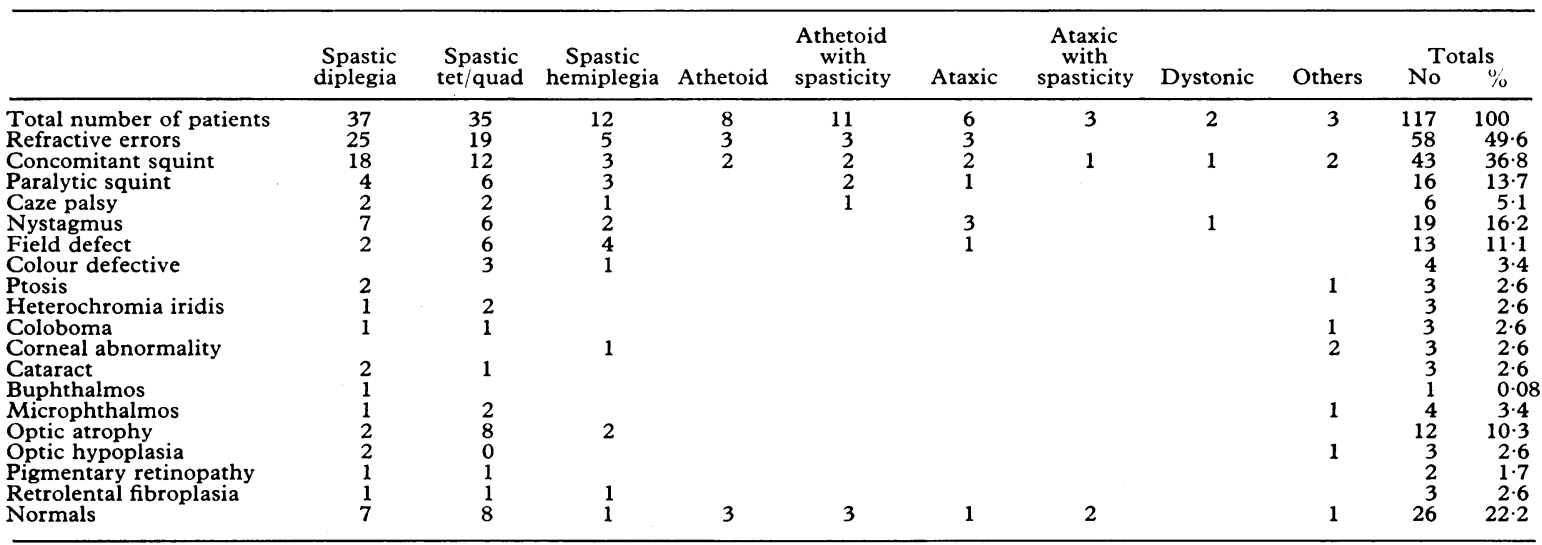

TABLE II-Incidence of major ocular abnormalities in principal types of cerebral palsy. Figures are in percentages of each type of cerebral palsy

\begin{tabular}{|c|c|c|c|c|c|c|}
\hline & $\begin{array}{c}\text { Refractive } \\
\text { error }\end{array}$ & $\begin{array}{c}\text { Concomitant } \\
\text { squint }\end{array}$ & $\begin{array}{c}\text { Paralytic } \\
\text { squint }\end{array}$ & Nystagmus & $\begin{array}{c}\text { Field } \\
\text { defect }\end{array}$ & Normals \\
\hline $\begin{array}{l}\text { Spastic diplegia } \\
\text { Spastic tet/quad } \\
\text { Spastic hemiplegia } \\
\text { Athetoid } \\
\text { Athetoid with spasticity } \\
\text { Ataxic } \\
\text { Ataxic with spasticity }\end{array}$ & $\begin{array}{l}67 \cdot 5 \\
54 \cdot 3 \\
41 \cdot 7 \\
37 \cdot 5 \\
27 \cdot 2 \\
50 \\
-\end{array}$ & $\begin{array}{l}48 \cdot 6 \\
34 \cdot 2 \\
25 \\
25 \\
18 \cdot 2 \\
33 \\
33\end{array}$ & $\begin{array}{l}10 \cdot 8 \\
17 \cdot 1 \\
\frac{25}{18 \cdot 2} \\
16 \cdot 7\end{array}$ & $\begin{array}{l}18 \cdot 9 \\
17 \cdot 1 \\
16 \cdot 7 \\
\frac{5}{50}\end{array}$ & $\begin{array}{l}5 \cdot 4 \\
17 \cdot 1 \\
\frac{25}{-} \\
\overline{16} \cdot 7\end{array}$ & $\begin{array}{r}18 \cdot 9 \\
22 \cdot 9 \\
8 \cdot 3 \\
37 \cdot 5 \\
27 \cdot 2 \\
16 \cdot 7 \\
66 \cdot 7\end{array}$ \\
\hline
\end{tabular}

associated with obvious ocular abnormalities. A further seven had latent nystagmus; this is not a common condition and the reason why such children should have a high incidence is not clear.

Field defects were found in 13 patients, six with hemianopia and the rest with constricted fields. The latter were associated in all but one case with retinal or optic abnormalities. Uveal abnormalities were seen in six cases and cataract in a further three.

There were only 26 children in whom the eyes could be said to be normal. The incidence of $78 \%$ abnormality is high

\section{References}

${ }^{1}$ Little WJ. Treatment of flat foot or spurious valgus. Lancet $1834 ; 44$ 679-84

2 Smith VH. Strabismus in cerebral palsy. Br Orthopt $\mathcal{7} 1965$;22:84-94.

${ }^{3}$ Fantl EW, Perlstein MA. Ocular refractive characteristics in cerebral palsy. Am $\mathcal{F}$ Dis Child 1961 ;102:34-41.

4 Simcoe CW. Cyclopentolate (Cyclogyl) toxicity. Arch Ophthalmol 1962 ; $67: 406-8$

5 Douglas AA. The eyes and vision in infantile cerebral palsy. Trans Ophthalmol Soc UK 1960;80:311-25.

(Accepted 17 fune 1980)
What are the likely effects on the victim of the ammonia sprays now often used in assaults on bank staff? What is the first-aid treatment?

Ammonia is a severe irritant of the conjunctiva and cornea. Splashes of fluid in the eyes cause severe pain, oedema of the conjunctiva, and clouding of the cornea that may result in varying degrees of permanent damage. Contamination of the skin may result in painful burns with corrosive damage. Inhalation may cause laryngeal oedema, pulmonary irritation, and possible oedema, which may be delayed. First-aid treatment is to wash the eyes copiously and thoroughly without delay using tap water or saline. The skin should also be flushed with warm running water. Embarrassment of the airways may require oxygen, assisted ventilation, or even emergency tracheostomy. Portable irrigation equipment could be in the form of polyethylene squeeze bottles or plastic saline infusion packs, and a tap shower spray may make irrigation of skin and face easier-it is important that the eyes in particular should be irrigated without delay and adequately. Further general information is given in Poisoning ${ }^{1}$ and details of treatment of bank staff sprayed with ammonia in the $B M \mathcal{F}^{2}$

1 Cooper P. Poisoning. London: Alchemist Publications, 1974

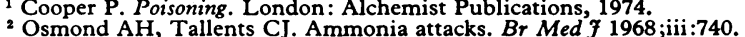

